\title{
Inge Crosman Wimmers, Proust and Emotion. The Importance of Affect in 'A la recherche du temps perdu'
}

\section{Geneviève Henrot Sostero}

\section{(2) OpenEdition}

\section{Edizione digitale}

URL: http://journals.openedition.org/studifrancesi/36657

DOI: 10.4000/studifrancesi.36657

ISSN: 2421-5856

\section{Editore}

Rosenberg \& Sellier

\section{Edizione cartacea}

Data di pubblicazione: 1 juillet 2005

Paginazione: 198

ISSN: 0039-2944

\section{Notizia bibliografica digitale}

Geneviève Henrot Sostero, «Inge Crosman Wimmers, Proust and Emotion. The Importance of Affect in 'A la recherche du temps perdu'», Studi Francesi [Online], 145 (XLIX | I) | 2005, online dal 30 novembre 2015, consultato il 19 avril 2021. URL: http://journals.openedition.org/studifrancesi/36657 ; DOI: https:// doi.org/10.4000/studifrancesi.36657

Questo documento è stato generato automaticamente il 19 avril 2021.

\section{(c)}

Studi Francesi è distribuita con Licenza Creative Commons Attribuzione - Non commerciale - Non opere derivate 4.0 Internazionale. 


\title{
Inge Crosman Wimmers, Proust and Emotion. The Importance of Affect in 'A la recherche du temps perdu'
}

\author{
Geneviève Henrot Sostero
}

\section{NOTIZIA}

INGE CROSMAN WIMMERS, Proust and Emotion. The Importance of Affect in 'A la recherche du temps perdu', Toronto-Buffalo-London, University of Toronto Press, 2003, pp. 278.

1 “La postérité donne de plus en plus raison à Proust: son oeuvre n'est plus lue seulement comme un monument de la littérature universelle, mais comme l'expression passionnante d'une sujet absolument personnel qui revient sans cesse à sa propre vie, non comme à un curriculum vitae mais comme à un étoilement de circonstances et de figures» (Barthes, Longtemps, p. 319). Raccogliendo l'ultimo invito di Barthes a leggere nel pathos il vero e profondo movente o motore della scrittura come della lettura proustiana, l'Autrice dà all'intimo e al privato il posto centrale nella sua riflessione: la vita interiore del protagonista della finzione. Gli apporti della filosofia e delle scienze sociali riguardo al pensiero contemporaneo delle emozioni. Rileggere Proust, oggi, alla luce di tali approcci interdisciplinari, convince maggiormente sul fatto che il romanzo si sviluppa attorno a un nucleo umano inconfondibile, che è l'esperienza personale delle emozioni: le passioni e le emozioni più forti non sono forse quelle che, di volta in volta, spingono e motivano la mise en intrigue, in quanto spiegano le azioni e reazioni dei personaggi principali, arricchendo inoltre suspense e sorpresa?

Dal drame du coucher, scena fondamentale del romanzo in cui l'eroe bambino esprime la sua angoscia di perdita, alla comédie de la rupture recitata dall'eroe adulto nei confronti della sua amante Albertine, il protagonista vive i suoi rapporti con gli altri sull'onda di un'insostenibile angoscia, che trapela anche attraverso la lettura della memoria involontaria. Le 183 pagine di saggio ripercorrono scene chiave e terni trasversali legati 
da un comune denominatore: l'emozione. Chiudono il volume 75 pagine di note completate da una bibliografia e da un indice di temi e nomi. 